regardless of cutoff $(\leq 0.5$ and $\leq 0)$. In patients achieving remission, there was a numerically greater improvement in HAQ-DI with sarilumab vs placebo (Pbo). Even if patients did not achieve remission or LDA, the sarilumab group had generally greater numerical improvements in $\mathrm{HAQ}-\mathrm{DI}$ vs $\mathrm{Pbo}$.

Conclusions: Achieving LDA or remission, or absence of radiographic progression, was associated with overall greater improvement in physical function. Irrespective of whether patients achieved remission or LDA, sarilumab + MTX showed greater improvements in HAQ-DI than Pbo + MTX.

Acknowledgements: This study was sponsored by Sanofi Genzyme and Regeneron Pharmaceuticals, Inc. Editorial support was provided by MedThink SciCom and funded by Sanofi Genzyme and Regeneron Pharmaceuticals, Inc. Disclosure of Interest: M. Genovese Grant/research support from: Roche, Sanofi, GlaxoSmithKline, R-Pharma, RuiYi, and Bristol-Myers Squibb, Consultant for: Roche, Sanofi, GlaxoSmithKline, R-Pharma, RuiYi, and Bristol-Myers Squibb, H. van Hoogstraten Shareholder of: Sanofi Genzyme, Employee of: Sanofi Genzyme, W. Kampman Shareholder of: Regeneron Pharmaceuticals, Inc, Employee of: Regeneron Pharmaceuticals, Inc, S. Jayawardena Shareholder of: Sanofi Genzyme, Employee of: Sanofi Genzyme, T. Huizinga Consultant for: Sanofi, Roche, and Abblynx.

DOI: 10.1136/annrheumdis-2017-eular.3513

\section{FRI0243 SIRUKUMAB TREATMENT REDUCES LEVELS OF IRON-REGULATORY PROTEINS AND AMELIORATES INFLAMMATION-ASSOCIATED ANEMIA IN RHEUMATOID ARTHRITIS PATIENTS}

M. Loza ${ }^{1}$, K. Campbell ${ }^{1}$, K. Sweet ${ }^{1}$, B. Hsu ${ }^{1}$, S. Daga ${ }^{2}$, B. Dasgupta ${ }^{1}$ ${ }_{1}^{1}$ Janssen Research \& Development, LLC, Spring House, PA, United States;

${ }^{2}$ GlaxoSmithKline, Uxbridge, United Kingdom

Background: Anemia of chronic disease, a common comorbidity of rheumatoid arthritis (RA), is detrimental to patients' (pts) quality of life, productivity, and long-term health.

Objectives: Sirukumab (SIR), a human monoclonal antibody that selectively binds to the IL-6 cytokine with high affinity, has recently demonstrated efficacy in RA. It was hypothesized that SIR, compared to placebo (pbo) and tumor necrosis factor-inhibitors (TNFi), increases hemoglobin $(\mathrm{Hb})$ concentrations in RA pts by decreasing levels of iron-scavenging proteins and increasing transferrin levels, thus ameliorating anemia. This hypothesis was tested in post hoc analyses of 4 phase 3 studies of SIR in RA: SIRROUND-M (methotrexate [MTX] inadequate responders [IR]); -D (disease-modifying antirheumatic drug [DMARD] IR); -T (TNFi-IR); - H (MTX-IR, monotherapy).

Methods: Standard hematology measurements, including $\mathrm{Hb}$ levels, were made throughout the studies by a central laboratory. Anemia was defined as $\mathrm{Hb}$ levels $<125 \mathrm{~g} / \mathrm{L}$ (males) and $<115 \mathrm{~g} / \mathrm{L}$ (females). In a subset of pts, iron-regulatory proteins (hepcidin, haptoglobin, hemopexin, transferrin) were measured in serum at baseline (BL) and Wk 4 using the SomaLogic SOMAscan ${ }^{\mathrm{TM}}$ platform (for SIRROUND-M, -D, -T, and -H studies, respectively: SIR 100mg q2w, $\mathrm{n}=61,205$, 136, 0; SIR 50mg q4w, $n=61,201,128,100$; pbo, $n=0,118,56,0$; adalimumab [ADA], $\mathrm{n}=0,0,0,98$ )

Results: SIR consistently reduced the prevalence of anemia to a greater extent than was observed for pbo $(p<0.05$; eg, in SIRROUND-D, anemia decreased from $25 \%$ of pts at $\mathrm{BL}$ to $10 \%$ at Wk 16 post-treatment with SIR $50 \mathrm{mg}$ q $4 \mathrm{w}$ vs increase from $24 \%$ of pts to $28 \%$ with pbo) and ADA (SIRROUND-H). Across studies on SIR $50 \mathrm{mg} \mathrm{q} 4 \mathrm{w}$, increases in $\mathrm{Hb}$ levels ranged from $7 \pm 10$ to $10 \pm 11 \mathrm{~g} / \mathrm{L}$ (mean $\pm S D$ ) through Wk 16; however, greater changes were seen in pts anemic at $\mathrm{BL}(13 \pm 13$ to $16 \pm 12 \mathrm{~g} / \mathrm{L}$ increase). Significant $\mathrm{Hb}$ elevations were observed by Wk 2, with comparable results for SIR $100 \mathrm{mg}$ q2w. Statistically significant increases in $\mathrm{Hb}$ levels were not observed with ADA (Fig.1) or pbo, regardless of $\mathrm{BL}$ anemia status. Changes in Hb levels with SIR were independent of changes in RA disease activity. Mean haptoglobin levels were modestly higher at $B L$ in RA pts with anemia compared to pts without anemia. Across studies, both SIR doses similarly strongly decreased levels of hepcidin, haptoglobin, and hemopexin and increased transferrin levels at Wk 4, regardless of $\mathrm{BL}$ anemia status. The modulation of these proteins by ADA was considerably less (Fig.1) and by pbo non-significant. After SIR treatment, greater decreases in hepcidin levels were consistently observed in pts with vs without BL anemia across studies by Wk 4 .
A

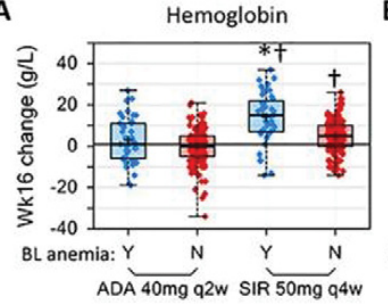

B

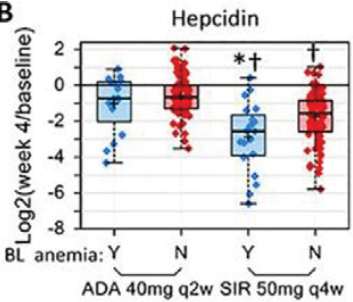

Figure 1. For the SIRROUND-H study, changes in (A) hemoglobin (week 16 change from baseline in $\mathrm{g} / \mathrm{L}$ ) and (B) hepcidin ( $\log _{2}$ (week $4 /$ baseline)) are plotted for each available patient, stratified by treatment group and baseline (BL) anemia status ( $\mathrm{Y}$, blue; $\mathrm{N}$, red). ${ }^{*} \mathrm{p}<0.05$ for baseline anemia $Y$ vs. $N$ within treatment group; $+p<0.05$ vs. adalimumab, within baseline anemia group. ADA, adalimumab; SIR, sirukumab.
Conclusions: SIR consistently increased Hb levels in RA pts (DMARD-IR, TNFi$I R$, monotherapy), most prominently in pts with $B L$ anemia, resulting in significant reductions in the prevalence of anemia. These effects were independent of the extent of improvement in RA disease activity, suggesting additional benefits of SIR beyond clinical response in RA. By inhibiting IL-6, SIR may decrease key iron-regulatory proteins, such as hepcidin, and shift homeostasis towards an increase in the pool of iron available for red blood cell $\mathrm{Hb}$, thus ameliorating anemia of chronic inflammation associated with RA.

Disclosure of Interest: M. Loza Employee of: Janssen Research \& Development, LLC, K. Campbell Employee of: Janssen Research \& Development, LLC, K. Sweet Employee of: Janssen Research \& Development, LLC, B. Hsu Shareholder of: Janssen Research \& Development, LLC, Employee of: Janssen Research \& Development, LLC, S. Daga Shareholder of: GlaxoSmithKline, Employee of: GlaxoSmithKline, B. Dasgupta Employee of: Janssen Research \& Development, LLC

DOI: 10.1136/annrheumdis-2017-eular.3570

\section{FRI0244 LOW DOSE OF RITUXIMAB IS EFFECTIVE FOR MAINTENANCE OF CLINICAL REMISSION OR LOW DISEASE ACTIVITY IN PATIENTS WITH RHEUMATOID ARTHRITIS}

N. Avgoustidis, I. Flouri, C. Adamichou, E. Kabouraki, A. Eskitzis, P. Kyfonidou, I. Papalopoulos, A. Fanouriakis, A. Repa, N. Kougkas, G. Bertsias,

P. Sidiropoulos. Department of Rheumatology, Clinical Immunology and Allergy, University Hospital of Heraklion, Crete, Greece, Heraklion, Greece

Background: Although existing data support the effectiveness of the low dose regimen (LDR, 1gr every 6 months) of rituximab as initial treatment for active rheumatoid arthritis (RA) (2), it is unknown whether this regimen may be used to maintain the therapeutic effect in patients achieved clinical remission or low disease activity (LDA) upon treatment with conventional rituximab regimen (2gr every 6 months)

Objectives: To evaluate the effectiveness of the rituximab LDR for maintenance of clinical remission and/or LDA in patients with RA in clinical practice.

Methods: Long-term prospective study of RA patients who received rituximab in the Rheumatology Department of the University Hospital of Heraklion during 03/2005-07/2016. All patients on clinical remission [DAS 28 (ESR) <2.6] or LDA [DAS28 (ESR) <3.2] for at least 12 months were treated with the LDR after obtaining verbal consent

Results: We analyzed 247 patients who received conventional rituximab regimen, of median age (IQR) 62 (54.3-70.4)years, females (84\%), disease duration 9.6 (5.6-18.3) years, $52 \%$ seropositive (RF or anti-CCP). Patients have had failed in (median) $3(2-3)$ non-biologic (nbDMARDs) and $1(1-2)$ biologic DMARDs (bDMARDs) before rituximab initiation. At baseline of rituximab treatment, $58.3 \%$ and $91.1 \%$ of them were on steroids and (nbDMARDs) respectively, while the disease activity was high [mean DAS28 (ESR): 5.84 (5.20-6.49)] and they had impaired physical functioning [mean HAQ: $1.0(0.63-1.38)$ ].

Overall, 27/247patients (11\%) received the LDR. Before the initiation of LDR, the duration of rituximab treatment was 24 (18-48) months and cumulative rituximab "exposure" was 8 (6-15) gr. At the time of LDR initiation, disease activity [DAS28 (ESR)] was $2.8(2.2-3.6)$ and HAQ: $0(0-0.4)$, while the time needed for achieving remission or LDA was18 (8-23) months. The median duration of follow-up of patients on LDR was $12(6-20)$ months. $23(85 \%)$ of patients remained in remission or LDA with median DAS28 (ESR) $2.85(2.23-3.52)$ and HAQ 0 (0-0.5) at last follow-up. Only $3(11 \%)$ of the patients experienced an increase of DAS28 $(>1.2)$ and $2(7 \%)$ of patients return to conventional dose.

Conclusions: In clinical practice, RA patients who achieved remission or low disease activity with conventional dose of rituximab may sustain clinical responses if treated with LDR. These preliminary findings support the use of LDR as maintenance treatment regimen and this may allow cost savings. (1)

References:

[1] Gianfranco Ferraccioli et al.Could we use a lower dose of rituximab to treat rheumatoid arthritis in clinical practice: pros and cons? Arthritis Res Ther. 2016; 18: 126

[2] Chatzidionysiou K, et al. Effectiveness of two different doses of Rituximab for the treatment of rheumatoid arthritis in an international cohort: data from the CERERRA collaboration. Arthritis Res Ther. 2016; 18:50.

Disclosure of Interest: None declared

DOI: 10.1136/annrheumdis-2017-eular.4958

\section{FRI0245 ABATACEPT RETENTION RATES AND PROGNOSTIC FACTORS OF RETENTION IN PATIENTS WITH RHEUMATOID ARTHRITIS: 2-YEAR RESULTS FROM THE REAL-WORLD ACTION STUDY}

$\underline{\text { R. Alten }}{ }^{1}$, H.-M. Lorenz ${ }^{2}$, X. Mariette ${ }^{3}$, H. Nüßlein ${ }^{4}$, M. Galeazzi ${ }^{5}$, F. Navarro ${ }^{6}$, M. Chartier ${ }^{7}$, Y. Elbez ${ }^{8}$, C. Rauch ${ }^{9}$, M. Le Bars ${ }^{7}$. ${ }^{1}$ Schlosspark-Klinik University Medicine, Berlin; ${ }^{2}$ University Hospital, Heidelberg, Germany; ${ }^{3}$ Université Paris-Sud, Paris, France; ${ }^{4}$ University of Erlangen-Nuremberg, Nuremberg, Germany; ${ }^{5}$ University of Siena, Siena, Italy; ${ }^{6}$ Hospital Universitario Virgen Macarena, Seville, Spain; ${ }^{7}$ Bristol-Myers Squibb, Rueil-Malmaison; ${ }^{8}$ Excelya, Boulogne-Billancourt, France; ${ }^{9}$ Bristol-Myers Squibb, Munich, Germany

Background: The ACTION (NCT02109666) study was designed to provide 